\title{
ENHANCING COMPETITIVENESS BY APPLYING AN INTEGRATED RISK MANAGEMENT APPROACH
}

\author{
P. Biolcheva* \\ Department Industrial Business, UNWE, Sofia, Bulgaria
}

\begin{abstract}
To maintain their competitiveness, business organizations need not only to rely on innovation, sales and good marketing. An important condition is to maintain their reputation, ensure business continuity, avoid leakage and loss of assets. This also outlines the importance of risk management. Effective risk management is a mandatory element of overall management at organizational level. The integration of different operating systems with the risk management system makes it easier to identify, analyze and manage all risk factors. The purpose of this paper is to outline the benefits of using an integrated risk management system as well as the relevance of information products to business organizations. Empirical research, among business organizations with a different subject of activity, is used to achieve the goal. The results show the effect on the stability of the organizations and their competitiveness.
\end{abstract}

Key words: Organization, Risk identification, Organization process, ERP

\section{INTRODUCTION}

One of the basic requirements for each business is to prevent breakthroughs in the core business processes running in the organization. This is largely associated with risk avoidance and proper and timely risk management. Modern risk management approaches require predictive management combining an analysis of capabilities, probabilities, risk and vulnerability. Risk management must be integrated into every operation, process, and activity at the company level. In this way, it can achieve a good degree of stability, ensuring business continuity, and hence a better competitiveness of the organization.

\section{RELATIONSHIPS BETWEEN RISK AND COMPETITIVENESS}

Competitiveness is what guarantees the achievement of long-term stability in the business system. Competitiveness is a complex and multifaceted category that reflects the company's internal capability to achieve high

\footnotetext{
*Correspondence to: Petya Biolcheva, Department Industrial Business, UNWE, Sofia, ul. "8-mi dekemvri", 1700 Studentski Kompleks, Sofia, Bulgaria, email p.biolcheva@unwe.bg, mob.0887695738
}

results. It depends on a number of interrelated elements of the external and internal business environment. Among the most important elements can be distinguished: the nature of competition, the security of resources; intercompany and intracompany relationships; customer behavior and many others. Building stable competitiveness depends on the organization's ability to operate and to be flexible and adaptable to changes in the market environment (1). Increasing company competitiveness is critical to defining opportunities (2). That is where the relationship between competitiveness and risk management comes from. Risk management focuses on minimizing future negative events based on decisions currently being made. The right approach to assessing opportunities greatly enhances the success of corporate goals. Various authors are working on the issues assessment, including: Ceyhun Ozgur, William D. Stevenson (2007)(3), Handfield, Walton, Sroufe, Melnyk, (2002) (4), R Martin, RL Martin - 2009 (5). In order to better outline the relationship between competitiveness and risk, it is also necessary to consider the nature of risk management. The goal of risk management is to create maximum value for each of the organization's activities. Risk 
BIOLCHEVA P.

management policy is driven by the quest to explore any growth or decline potentially contained in all the factors that can influence the organization. Risk management supports the achievement of organizational goals by providing the framework for a controlled, consistent and future-oriented activity. This improves decision-making, planning and prioritization by providing a structured and comprehensive understanding of business activity, changing movements and trends, and opportunities for individual projects (or threats to them). Another effect that can be highlighted is the reduction of fluctuations in secondary activities. From here can be highlighted the adequate opportunities related to increasing the competitiveness of the organization. In addition to prioritizing opportunities, risk management also has a bearing on optimizing operational efficiency and hence protecting assets and improving corporate image, (6) which has a direct impact on the competitiveness of the organization. There are a number of studying approaches to the organization of the risk management process, as well as ISO 31000: 2018 Risk Mamagement, (7) which provides the framework for its implementation. In summary, the risk management process goes through the following stages: identification, analysis, evaluation, management and control. The UR process described here follows the consistency of the Risk Management Standard based on ISO31000.

When launching the risk management process, it is necessary to take into account the strategic objectives related to the long-term perspective of the company. From this point of view, it is necessary to pay attention to the risks that accompany the development of the company. Still at a perspective stage and opportunities to take measures for adequate risk management related to avoiding inappropriate production, counterparts and markets, etc.

Next is the so-called "Risk Assessment". According to ISO / IEC 31000, this is the overall process of risk analysis and assessment. With regard to the analysis, it begins with the identification of all external and internal risk factors that threaten the activity and development of the organization or may exhibit such characteristics in the future. That is the way, it can be determined whether the business organization can be vulnerable to uncertainty and uncertainty. Risk identification is conducted consistently and methodically to ensure that all activities that are relevant to the organization and the resulting risks are covered. Any uncertainty associated with these activities must be recognized and categorized.

The next step of the risk assessment is its description. It identifies the identified risks in a structured format. Having a clear structure is necessary to achieve a comprehensive identification, description and risk assessment. Taking into account the expected magnitude of the consequences and the frequency of occurrence for each risk, it may be possible to prioritize certain risks that should be subject to detailed and prioritized analysis. The description of the risks associated with business activity and decision-making can be divided into different categories such as strategic, tactical, operational.

It is important to define the methods and techniques for risk analysis. There are many known in theory and practice based on different criteria. Among the most commonly used are: Interconnection Modeling, SWOT Analysis, Tree of Events, Business Continuity Planning Planning, BPEST Analysis, Optional Modeling, Decision Making in Risk and Uncertainty, Statistical Analysis, Trend Development and Dispersion, Threat Analysis, Error Analysis, FMEA Analysis, and more.

The process continues with the risk assessment. Depending on company goals, it may have a different character. The risk is assessed quantitatively, semi - quantitatively or qualitatively depending on the likelihood of occurrence and possible consequences. The outcome of the risk analysis process is used to create a profile that helps the risk to be classified and to develop a tool for prioritization. This process allows the risk to be linked to the particular business activity it affects, to describe the basic control procedures and to identify the areas that need to increase / reduce / redistribute resources for risk control.

In this way, the stage at which it is necessary to implement measures against the risks is reached. They aim to achieve a positive risk reduction. Measures are largely risk control / mitigation, transfer, prevention, diversification, etc. are also used. Applying risk treatment measures should continue until an acceptable level of residual risk is reached. 
It should be borne in mind that risk management is a rotation process that requires monitoring and control. Accountability and control procedures are needed to ensure effective risk identification and assessment as well as take the necessary measures. Periodic review of policy and compliance with standards is needed to identify improvement opportunities. It should not be forgotten that organizations are dynamic and operate in a dynamic environment. Changes in the environment must be recognized in order to make timely changes to the system.

In order to be able to effectively manage risk, it needs to be part of a common, integrated process management system that includes all major business processes and systems and has a significant place in each activity.

\section{INTEGRATED MANAGEMENT APPROACH}

The Integrated Management Approach is the subject of many research studies and is also a key in Industry 4.0. It is based on modern information systems for business process management (ERP, CRM, HR, etc.). Following the development of business organizations, the integration of all processes and systems is a natural move that needs to be achieved. A key place in the process of managing integrated approaches is the place of risk in each of them in logistics management, production processes, finance, human resources, legal activities, IT, security, marketing and planning, etc.

Applying an integrated business management approach to business organizations implies coverage of all aspects of the business, more complete and purposeful achievement of corporate goals, harmonization of all processes. Through an integrated management approach optimization of time, resources and resources in organizations is achieved. Process integration is often defined as a "pool of interrelated processes that share a unique pool of human, informational, material, infrastructure, and financial resources to achieve a set of goals that are relevant to the satisfaction of a number of stakeholde (8).

Through the integrated management system, business organizations have the ability to combine customer satisfaction, optimize processes, meet regulatory requirements, and other benefits. Most often it offers management in several different spheres. For example: quality management (ISO 9000), environment (ISO 14001), safe working conditions (OHSAS 18001), safe food production (HACCP), energy efficiency that simultaneously meets the requirements of several standards encompassing all processes within an organization, allowing the optimal achievement of its goals and contributing to its continuous improvement, development and improvement. Thanks to the integrated management approach, it is easier to identify potential risks, and therefore easier and more efficient to manage (8).

The widest application in the integrated approach can be found in the so-called ERP / Enterprise Resource Planning. ERP's scope covers the integrated management of core business processes within the organization. ERP is a business management software solution that is used to collect, store, manage, analyze data on the many different business activities in the organization. ERP provides an integrated and continually updated overview of core business processes using common databases supported by a database management system. ERP systems track business resources - cash, raw materials, production capacity. The individual parts of the system continuously exchange data in different departments (production, supply, sales, accounting, etc.) that provide the data (9). ERP facilitates the flow of information between all business functions and manages relationships with external stakeholders. In this way, every employee, regardless of the post, department, division or branch, has access to all the information intended for him / her (10). This way, it can work with all the necessary modules and its activities are reflected in the relevant modules chronologically recorded (11).

The ERP scope covers functional areas (socalled ERP modules) such as:

- Finance and accounting

- Human Resources

- Production

- Order processing

- Supply Chain Management

- Project management

- Managing customer relationships

- Data services

The advantages of ERP stand out from the fact that employees can perform their duties in the most efficient way, allocating them on projects, assignments; creating a sophisticated and organized program and tracking it for yourself. Next, the ERP system builds a global 
view of business, enabling real-world identification of processes that need to be improved, what is the actual productivity of departments. Regarding financial transactions, full accountability and automatic recording in financial books is ensured, allowing constant and up-to-date information on the company's business status as well as its interaction with counterparties. Provides automation of original business operations by automatically filling in existing data in subsequent documents. Last but not least, it improves the customer service, the possibility of establishing constant feedback and chronologically arranged communication (12).

When deepening on the different modules of integrated management, the risk position can be sought for each of the activities.

- CRM software - customer relationship. The main applications of this module are based on a pool of all available counterparty information; calendar of the organizational process and allocation of specific tasks.

Risky location in this software aims to reduce losses from unfair or insolvent clients. Along with attracting and retaining new clients, organizations' security mechanisms must ensure their reliability. In this part, the software may be linked to a commercial register where information is available on the financial status of corporate customers, owners, affiliates, etc., and also provides information on publications on the organization's internet site and / or its owners.

- Warehouse Program - This module targets activities such as warehouse management, tracking of available items, product features database, quantity information, dimensions, units, packs, barcode reader.

The risk location of storage space management can be searched for threats related to the infrastructure of the room and disturbances in the conditions under which it works (temperature, lighting, etc.); the state of the available materials and the risks of unnoticed deception in their properties and characteristics.

- Sales Process Management Software - Here are some basic areas. In the first place, bidding with its components: signing a purchase / sale transaction; dispatching; payments. Second billing; declarations of conformity; sales by expedition and / or shipping; merging purchases / sales; calculation of transport in offers and sales; claims and returns.

The risk location in this module can be found in the legality of the transactions concluded, the compliance between the guarantees of compliance and the actual condition of the products or services; transport risks; the risk of claims and discrepancies between bids and actual deliveries, etc.

- Corporate email server - used to receive and distribute emails, ie. automatic filtering by predefined features sort all emails sent from a given counterparty to a corresponding folder; creating emails; the ability to transfer files from the system;

The risks in this module related to the use of corporate email are primarily focused on the ability to access information classified as a company secret; the risk of malicious external interference, etc.

- HR - the main application here is related to services such as: recruitment and recruitment, contract preparation, training, remuneration, sickness benefits, leave, task planning, attestation, staff release.

Staff is both the most valuable asset for each company and its greatest threat. The most common staff-related risks can be summarized as follows: the risk of unfair action; the risk of lack of ownership of the organization's goals; the risk of exporting information; the risk of system failures in the work process, etc.

- Project management software, used as a tool to provide opportunities such as: pooling of tasks, resource allocation, real-time tracking.

Achieving company goals by developing them in the form of projects and key to the organization's development. The main groups of risks here are related to project risk management, which is multifaceted - time, financial, risk of misconceived idea, inappropriate development team, etc.;

- Document turnover - Main groups of activities that are performed in connection with the processing of incoming and outgoing documents are related to activities such as grouping of documents, document protection under internal rules, data protection regulation, data loss prevention, organization of archiving and destruction of documents, defining access according to the level of secrecy in the organization. 
The place of risk associated with document processing is primarily related to the proper definition of access to relevant information, depending on the need-to-know principle. In addition, it is important here to limit the possibility of leakage of information, whether electronically or through paper copies.

- Production software - contains detailed specifications with drawings and product diagrams, possible alternatives to product parts replacement; production assignments that can be integrated into sales contracts, production protocols with automatic resource input capabilities;

Risk here is primarily the realization of a poor quality product; risk associated with discrepancy between the set parameters and others.

- Accounting software - contains applications such as transaction logs, assignment of project and task costs, input of various balances, register of waiting documents incoming / outgoing mail, etc .; the risk here is related to the possibility of financial distortions and abuses.

The potential risks described here are not exhaustive. The goal is to show that when working on any of the business process management systems, an additional list of potential risks can be integrated which, according to the specific situation, alarm for an increased level of potential threats. That, on its own, will increase the early identification of risk threats, which makes it possible to take preventative measures at the earliest possible stage of the process. Thus, the level of risk exposure can be reduced to a good extent.

Typical of risk management is that the occurrence of a risky event is always accompanied by multiple direct and / or indirect risk events, the chain effect is prevented with a lot of effort and means. The purpose of risk integration is to show the fullest possible list of potential risks that can be incurred in carrying out an operation or process, both in the specific business activity being carried out and in all others that have a direct or indirect treatment.

The elements of parts of company process management software shown here are only a small sample of the full list of organizations that work with. It is important to note that the specificity of business process management software should be strictly profiled, depending on the specifics of the activity, the form of organization, the ownership, the size of the organization, the industry, the internationalization, etc. Risk integration in each of the business organization activities generates improvements in the performance of the organization's internal business processes, which have a crucial role to play in creating value for all stakeholders. Thus, the outcome of risk management is multifaceted, reaching a pool of processes that consume the same resources and achieve goals in all organizational goals. The integration of risk into the overall company software product improves the effectiveness of planned and implemented risk prevention and treatment measures; the economic efficiency of the proposed measures and their legality.

\section{METHODOLOGY OF THE SURVEY}

The survey aims to verify the views of business organizations on the benefits of risk integration in individual business processes in particular and the impact on the competitiveness of the organization as a whole. The methodology of the study is based on the literature analysis and is organized in the form of a short survey. The survey was conducted through a structured online questionnaire providing anonymity of responses and privacy. Respondents are 15 large companies in the service sector. The empirical study was conducted in the second quarter of 2019.

The questions in the study are related to the availability of integrated company software that combines at least three of the local company programs, as well as the respondents' opinion on the applicability and the place of risk in the functioning of each and every part of the software and in its entirety.

The questions are structured in a closed-ended manner, with directional responses from which respondents choose the right one for them. The scale of the majority of the questions is fivestep, allowing respondents to choose between the answers "definitely yes, rather to, it is hard to say, rather not, definitely not.

\section{RESULTS FROM EMPIRICAL STUDY}

The results of the survey show that only $20 \%$ of the respondents have a fully developed ERP system with active and interconnected software products. For the most part (40\%) large organizations still work with separate software products without any link between them. That, on the one hand, speaks of a more difficult organization of overall management but, on the other hand, a prerequisite for finding the place 
of risk in the next step ahead of companies, namely the integration of processes. The degree of process integration is illustrated in Figure 1.

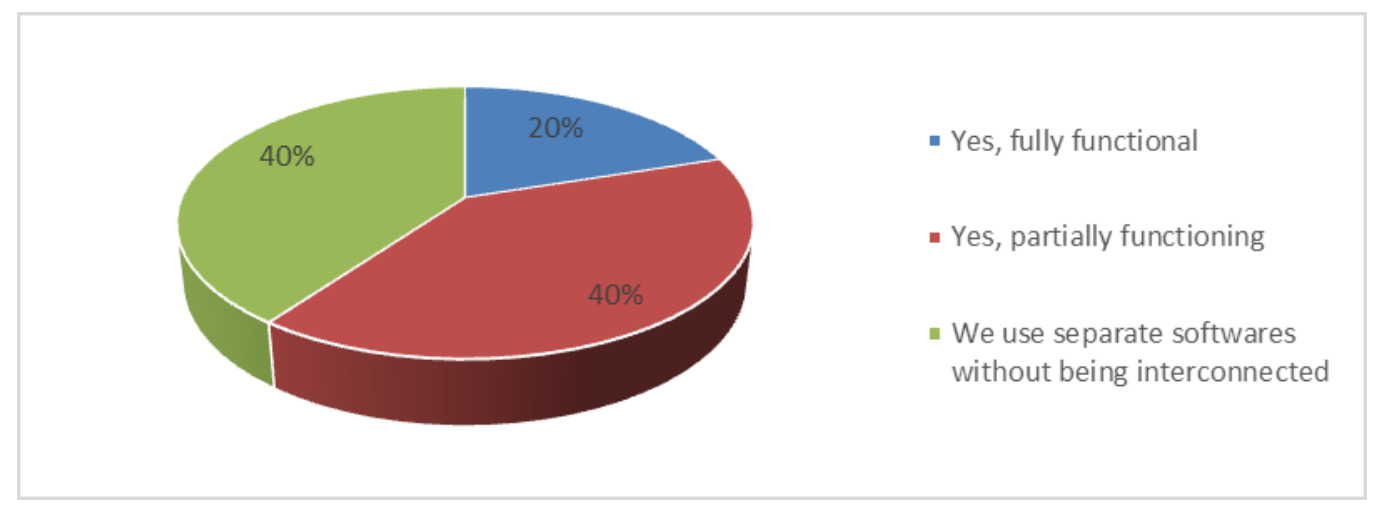

Figure 1. Degree of integration in company processes

In order to deepen the survey, it is important to find out what responders think of the place and significance of risk in the overall activity of organizations and in each activity and process separately. Only about $15 \%$ of respondents have risk management integrated into all business processes in the organization. The vast majority of companies rely on risk management experts in key departments to organizations. This is, in turn, a prerequisite for increasing the degree of risk in un-analyzed activities that may have a negative impact on core business processes. The place of risk is in all tested organizations is illustrated in Figure 2.

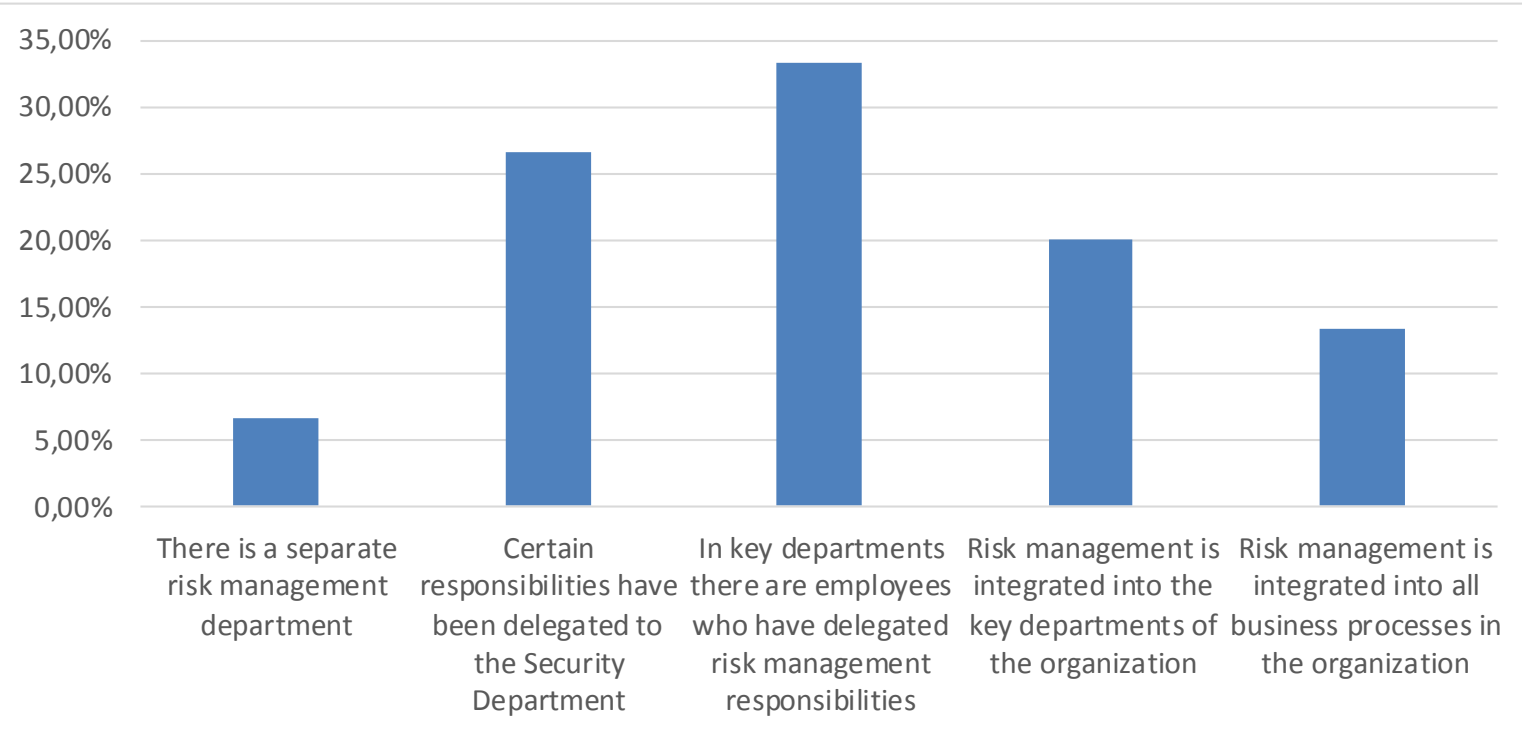

Figure 2. The location of the risk in the organization

However, in their majority (about $80 \%$ ) of respondents find it necessary and useful to integrate the risk. According to their ideas, the integration of risk will be visualized in the operational activity, as in various operations in the software product, various potential events, related to the operation, are displayed on the screen. Thus, around 50\% of surveyed companies will increase the extent to which potential risk events will be identified. According to others, about $25 \%$ find it difficult to say whether risk identification will increase. Their arguments are limited to the fact that the visualized potential risk events are known and manageable, and the threats are primarily due to unforeseen risk events. Regarding the speed of operational activity and "aggravation" with extra time, for review and analysis of potential employee risks, respondents' opinions are contradictory. According to about $30 \%$, the time for operating activities will increase, which will slow down the core business 
processes. On the contrary, there are around $40 \%$, according to which there will be no major changes in the length of implementation time, with timely risk identification compensating for delays from different interruptions. Respondents' views on potential delays in the implementation of operational activities are illustrated in Figure 3.
Regarding the relationship between risk integration in all business processes and its timely prevention, the respondents' opinion is almost unanimous. Everyone thinks that risk prevention would be much better, and its management would be much more effective.

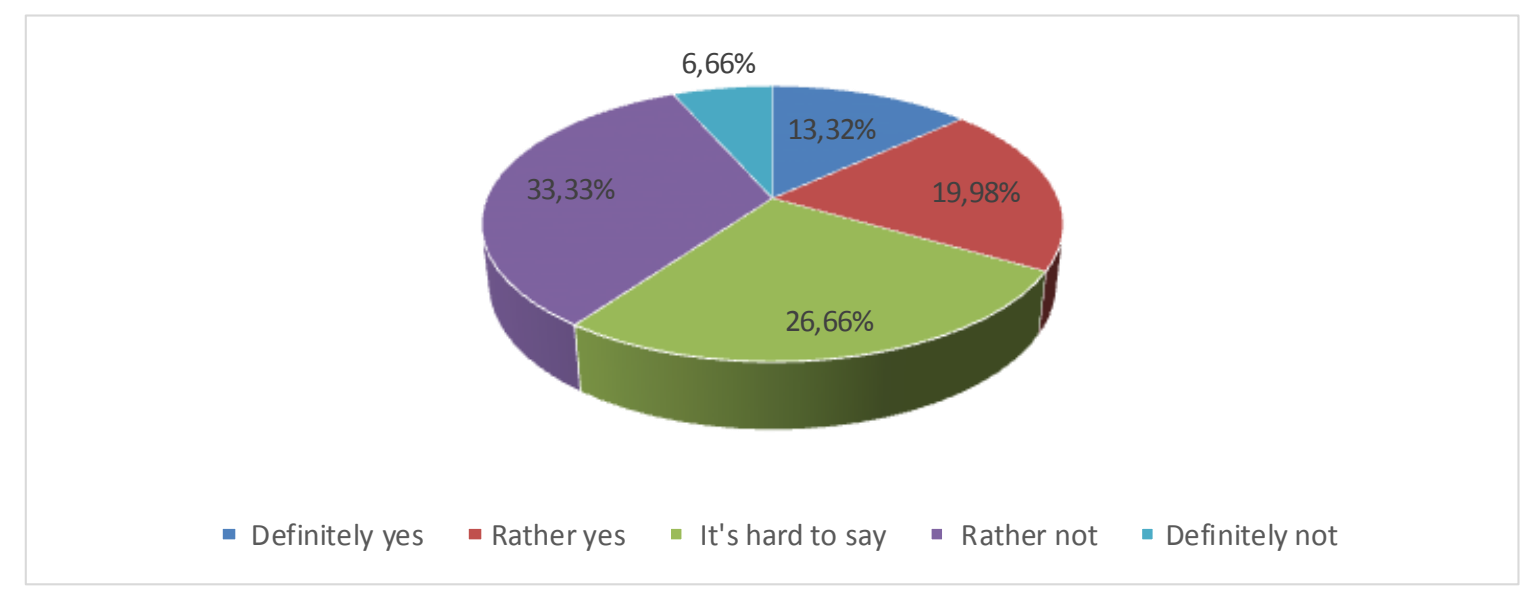

Figure 3. Delay in operational activity of the company as a result of risk integration

Research is also the relationship between risk integration in all business processes and the competitiveness of the organization. According to $53.33 \%$ of the respondents, competitiveness will increase, while $26.66 \%$ consider that the relationship is indirect and will not contribute direct results, $26.66 \%$ do not find any relation to the company's competitiveness.

\section{CONCLUSION}

The study shows that despite a number of issues that need to be clarified, the integration of risk has a place in each of the company's activities and processes. It is a natural move that business organizations need to take to be able to manage their risk in a targeted manner, avoiding risky events and interrupting key business processes and hence increasing their competitiveness.

\section{REFERENCES}

1. Jayachandran, S., Varadarajan, R., Does Success Diminish Competitive Responsiveness? Reconciling Conflicting Perspectives, 2006, [online] avalleble at: http://citeseerx.ist.psu.edu/viewdoc/download ?doi=10.1.1.1000.6333\&rep=rep1\&type $=$ pdf

2. Milusheva.,V., Podhod za otsenqvane na varmojnostite za povishavane na konkurentosposobnostta I opredelqne na upravlenski prioriteti (na primera na golemi firmi ot tsvetnata metalurgiq), Ikonomicheski I sotsialni alternativi, 2013, br.4, s. 63

3. Ceyhun Ozgur, William D. Stevenson, Introduction to Management Science With Spreadsheets, Publisher: McGraw-Hill/Irwin, 2007
4. Handfield, Walton, Sroufe, Melnyk, 2002, [online] Available at: http://cscmp.org/ downloads/public/academics/scmec.

5. Martin, R., Martin RL, The design of business: Why design thinking is the next competitive advantage, Harvard Business Press, 2009

6. A Risk Management Standard, Federation of European Risk Management Association, 2003

7. ISO 31000:2018 Risk Management Guidelines, provides principles, framework and a process for managing risk.

8. Nenova, A., Integrirani sistemi za upravlenie na kachestvoto, okolnata sreda, bezopasnostta i zdraveto $\mathrm{v}$ biznes organizatsiite, Nauchni trudove, Rusenski universitet, 2013,tom 52, seria 1,2, s.253

9. Almajali, Dmaithan (2016). "Antecedents of ERP systems implementation success: a study on Jordanian healthcare sector". Journal of Enterprise Information Management. 29 (4): 549-565. doi:10.1108/JEIM-03-2015-0024

10. Radovilsky, Zinovy (2004). Bidgoli, Hossein (ed.). The Internet Encyclopedia, 2004, Volume 1. John Wiley \& Sons, Inc. p. 707. ISBN 9780471222026.

11. What is an ERP system?, Epnehedra-tk, available at:https://ephedratk.com/epп/\#149294646651 4-68189ab0-de91 